\title{
A culture-based analysis on the bacterial diversity in fresh rainwater in Kandy, Sri Lanka: A preliminary study
}

\author{
WAK Perera ${ }^{1}$, JMSD Jayalath ${ }^{1}$, DN Magana-Arachchi ${ }^{1}$
}

Introduction and Objectives: Rainwater harvesting systems is a possible alternative to diminished water resources in the dry zones of Sri Lanka. Nevertheless, how safe is rainwater? This study was conducted to identify culturable bacteria in rainwaterwhich may also be pathogenic.

Methods: In total, eight rainwater samples were collected from December to February in the Kandy city region: 5 samples from the National Institute of Fundamental Studies and one each from residential areas of Aniwatta, Lewella and Boowelikada. Pure rainwater was collected by placing sterile polypropylene bottles with a funnel in an isolated open space to avoid contaminants. On average, $70 \mathrm{~mL}$ of rainwater was collected and centrifuged at 3500 rpm for 10 minutes. The samples were inoculated within 24 hours as duplicates of supernatant and pellet onto LB media (Luria - Bertani) plates and incubated at $37^{\circ} \mathrm{C}$ for $24-$ 48 hours. Single colonies of different morphologies were selected and sub-cultured to obtain pure bacterial isolates. These were subjected to Gram staining and biochemical testing for identification.

Results: Morphologically, colonies ranging from cream, yellow to red with varying structures including circular, rhizoid and wavy margins were observed, consisting of both Gram-negative $(n=13)$ and positive bacteria $(n=27)$ in the form of rods, cocci and coccobacilli. Bacterial colonies of different morphologies were isolated in each rainwater sample (RW) as follows: RW1 (n=6), RW2 (n=2), RW3 (n=9), RW4 (n=8), RW5 ( $=4)$, RW6 ( $\mathrm{n}=5)$, RW7 $(\mathrm{n}=3)$, RW8 $(\mathrm{n}=3)$, totaling 40 pure isolates. Tentatively identified organisms belonged to the genera Streptococcus (3 isolates), Staphylococcus (4), Pseudomonas (1), Bacillus (4), Methylococcus(1) and Micrococcus (1). Additionally, pathogenic bacteria such as Staphylococcus and Streptococcusreoccurred in $3 / 8$ samples.

Conclusions: A cause for concern is that some pathogenic bacteria were noted to be reoccurring in the rainwater samples. Analysis is ongoing in this study for further investigation into the rainwater bacterial diversity.

Keywords: Rainwater, bacteria, microbiome, Sri Lanka

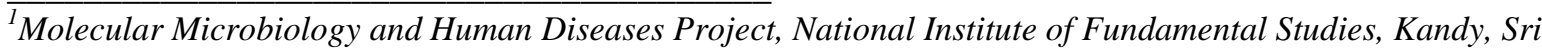
Lanka
}

Address for correspondence: Prof DN Magana-Arachchi. Telephone: +94772865367

Email:dhammika.ma@nifs.ac.lk (Dhttps://orcid.org/0000-0001-5825-4626 